\title{
Affectivity Profiling in Relation to Exercise: Six-months Exercise Frequency, Motivation, and Basic Psychological Needs Fulfilment
}

\section{Danilo Garcia ${ }^{1-5^{\star}}$, Trevor Archer ${ }^{2,3}$}

${ }^{1}$ Network for Empowerment and Well-Being, Sweden

${ }^{2}$ Blekinge Centre of Competence, Blekinge County Council, Karlskrona, Sweden

${ }^{3}$ Department of Psychology, University of Gothenburg, Gothenburg, Sweden

${ }^{4}$ Institute of Neuroscience and Physiology, University of Gothenburg, Gothenburg, Sweden

${ }^{5}$ Department of Psychology, Lund University, Lund, Sweden

\begin{abstract}
Background: In the past 10 years, several studies using the affective profiles model (i.e., combinations of high/low positive/negative affect) show that individuals with high positive affect profiles (i.e., self-fulfilling and high affective) report greater propensity to exercise compared to individuals with low positive affect profiles (i.e., selfdestructive and low affective). Nevertheless, these studies have not used objective measures of exercise frequency.

Objective: We investigated differences in exercise frequency six months back in time, motivation, basic psychological needs fulfillment, and if the effect of motivation and needs on training frequency was moderated by type of profile.

Method: 143 individuals at a training facility in the South of Sweden responded to the Positive Affect Negative Affect Schedule, the Behavioral Regulation in Exercise Questionnaire 2, the Basic Psychological Needs in Exercise Scale, and provided their membership number for the electronic tracking of their training frequency.

Results: Although there were no differences in exercise frequency, positive affect was negatively associated to external regulation and positively to autonomy, competence, and relatedness per se; both when negative affect was low or high. All other variables presented complex dynamic associations to affectivity. Training frequency was positively related to introjected regulation and competence among individuals with a self-destructive profile and negatively to relatedness among those with a high affective profile.

Conclusion: Future studies are needed in order to investigate objective measures of exercise frequency in relation to affectivity profiling. Importantly, the model allows the comparison of people who differ in one affectivity dimensions while keeping the other constant.
\end{abstract}

Keywords: Affective profiles model; Exercise motivation; Negative affect; Positive affect; Psychological needs; Training frequency

\section{Introduction}

The notion of the affective profiles model, coined by Archer and colleagues [1-4], suggests four possible profiles using combinations of individuals' experience of high/low positive/negative affect: (1) selffulfilling (i.e., high positive affect/low negative affect), (2) low affective (i.e., low positive affect/low negative affect), (3) high affective (i.e., high positive affect/high negative affect), and (4) self-destructive (i.e., low positive affect/high negative affect). During the last 10 years, this model of the affective system has been used to distinguish individual differences in positive (i.e., well-being) and negative (i.e., ill-being) biopsychosocial health [5-12]. Mainly, compared to individuals with a self-destructive profile, individuals with a self-fulfilling profile, experience higher subjective (i.e., satisfaction with life, harmony in life) and psychological well-being (e.g., self-acceptance, personal growth, purpose in life, autonomy). In addition, individuals with a self-fulfilling profile also experience higher levels of energy, and optimism along lower levels of stress, depression, anxiety, maladaptive coping, and external locus of control [13-20].

The affective profiles model's greatest advantage, however, is that it can be used as a framework for within comparisons, that is, to compare individuals that are similar in one of the two affectivity dimensions but differ in the other dimension [21]. For example, when individuals who experience similar levels of low positive affect but differ in their experience of negative affect (i.e., low affective vs. self-destructive) are compared to each other, researchers have found that high levels of life satisfaction are associated to decreases in negative affect as long as positive affect is low. In essence, the affective profiles model offers a person-centered representation of the affectivity system - a $2 \times 2$ model that is diametrically different than the notion of seeing positive affect and negative affect as either bidimensional or as unidimensional. A large number of studies during the past 10 years show that one of the most recurrent results is that individuals with high positive affect profiles (i.e., self-fulfilling and high affective) report greater propensity to exercise than individuals with low positive affect profiles (i.e., low affective and self-destructive). Nevertheless, all these past studies have used self-reports for the measurement of exercise frequency. This might present a problem because self-reported answers might, for example, be exaggerated, influenced by social desirability bias, rely on individuals

*Corresponding author: Garcia D, Network for Empowerment and Well-Being, Axel W. Anderssons Väg 8A, SE 371 62, Lyckeby, Sweden, Tel: +46 317864694 . E-mail: danilo.garcia@icloud.com

Received: April 28, 2016; Accepted: May 09, 2016; Published: May 16, 2016

Citation: Garcia D, Archer T (2016) Affectivity Profiling in Relation to Exercise: Six-months Exercise Frequency, Motivation, and Basic Psychological Needs Fulfillment. Clin Exp Psychol 2: 128. doi:10.4172/2471-2701.1000128

Copyright: ( 2016 Garcia D, et al. This is an open-access article distributed under the terms of the Creative Commons Attribution License, which permits unrestricted use, distribution, and reproduction in any medium, provided the original author and source are credited. 
memory, be inherently biased by the person's feelings at the time they filled out the questionnaire.

In the present study we had three aims. The first one was to replicate earlier findings showing differences in exercise frequency between individuals with distinct affective profiles. However, in contrast to all earlier studies, rather than self-reports, we used an objective measure of exercise frequency (i.e., training frequency measured electronically during the past six months). The second aim was twofold: to investigate differences between individuals with distinct affective profiles with respect to what motivates them to exercise (i.e., a motivation, external regulation, introjected regulation, identified regulation, and intrinsic regulation) and with respect to which basic psychological needs (i.e., autonomy, competence, and relatedness) are being fulfilled through their exercise regime. These aspects of exercise habits (i.e., exercise motivation and basic psychological needs fulfillment) have not being investigated before in relation to individuals' affective profiles. Moreover, also in contrast to earlier studies, we analyzed these differences by focusing on matched comparisons. That is, we investigated differences in, exercise frequency, exercise motivation, and basic psychological needs fulfillment between individuals who were similar in their experience in one affective dimension, but that differed in the other. In this way, we were able to examine what changes could be expected in relation to individual experience of one affectivity dimension while keeping the other constant: self-destructive vs. high affective (matching: high-high negative affect, differing: low-high positive affect), self-destructive vs. low affective (matching: low-low positive affect, differing: high-low negative affect), high affective vs. self-fulfilling (matching: high-high positive affect, differing: high-low negative affect), and low affective vs. self-fulfilling (matching: low-low negative affect, differing: low-high positive affect). As a further addition to earlier research, our third and final aim was to investigate if the effect of motivational dimensions and basic needs fulfillment on exercise frequency during the past six months was moderated by the individuals' type of affective profile.

\section{Method}

\section{Ethical statement}

The study was at first planned as part of a student thesis and the data on exercise frequency is a normal type of data gathered at the training facility. The Network for Empowerment and Well-Being's Review Board recommended that the present study required only informed consent from the participants.

\section{Participants}

A total of 158 individuals were recruited from a training facility in the South of Sweden. The final sample consisted of 143 (42 males, 101 females) participants with an age mean of $39.22(\mathrm{sd}=22.99)$ who answered all the questions (i.e., a dropout rate of 6.96\%). Besides responding to a battery of self-reports, all participants were asked to provide their gym membership number in order to track their training frequency six months before the study. Participants were informed that their participation was voluntary and confidential.

\section{Measures}

Exercise frequency: The number of times each participant was at the training facility for the last six months was recorded by an electronic entry system. This information was linked to the participants' gym membership number.
Affectivity: The Positive Affect and Negative Affect Schedule [22] requires participants to rate to what extent $(1=$ very slightly, 5 = extremely) during the last few weeks they experienced 10 positive (e.g., strong, proud, interested; Cronbach's $\alpha=0.84$ ) and 10 negative (e.g., afraid, ashamed, nervous; Cronbach's $\alpha=0.84$ ) affective states. The version here has been used in several previous studies among Swedes [23].

Motivation to exercise: The Behavioral Regulation in Exercise Questionnaire $2[24,25]$ comprises five subscales $(0=$ not true for me, 4 = very true for me) assessing amotivation (e.g., "I think that exercising is a waste of time"), external regulation (e.g., "I exercise because other people say I should"), introjected regulation (e.g., "I feel guilty when I don't exercise"), identified regulation (e.g., "I value the benefits of exercise"), and intrinsic regulation (e.g., "I exercise because it's fun"). The instrument was translated and then back translated by native speakers for this specific study. No discrepancies were found between the Swedish and the English versions. Cronbach's $\alpha$ in the present study were .65 for amotivation, 0.78 for external regulation, 0.78 for introjected regulation, 0.70 identified regulation, and 0.90 for intrinsic regulation.

Basic psychological needs fulfillment by exercise: The Basic Psychological Needs in Exercise Scale [26] is based on Selfdetermination Theory [27] and designed to assess perceptions of the extent to which ( $1=$ totally disagree, $5=$ very strongly agree $)$ a person experiences autonomy (e.g., "The exercise program I follow is highly compatible with my choices and interests"), competence (e.g., "I feel I have been making a huge progress with respect to the end result I pursue"), and relatedness (e.g., "I feel extremely comfortable when with the other exercise participants") in relation to their exercise habits. The instrument was translated and then back translated by native speakers for this specific study, no discrepancies were found between the Swedish and the English versions. Cronbach's $\alpha$ in the present study were 0.79 for autonomy, 0.80 for competence, and 0.84 for relatedness.

\section{Statistical procedure}

We divided participants' self-reported positive affect and negative affect scores into high and low using the median as reference point. This high/low categorization was then combined to group participants in one of the four affective profiles: self-destructive (low positive and high negative affect; $\mathrm{n}=35$ ), low affective (low positive and low negative affect; $n=41$ ), high affective (high positive and high negative affect; $\mathrm{n}=40$ ), and self-fulfilling (high positive and low negative affect; $\mathrm{n}=29$ ). Garcia et al. [23] have found the median split method (i.e., variable-oriented method) to be relatively similar to cluster analyses methods (i.e., person-centered approach) for the affectivity profiling of individuals. Thus, we found the median split method as appropriate in the present study. See Table 1 for mean and standard deviations in all variables for each profile and the whole sample.

For the first and second aim we conducted planned matched t-test for the investigation of differences in exercise frequency six months back in time, exercise motivation, and basic psychological needs fulfillment between individuals with distinct profiles. For the third aim, we conducted four correlation analyses, one for each profile, to investigate if the effect of both exercise motivation and psychological needs fulfillment (predictors) on individuals' training frequency six months back in time (outcome) was moderated by the individuals' type of affective profiles (moderator). 


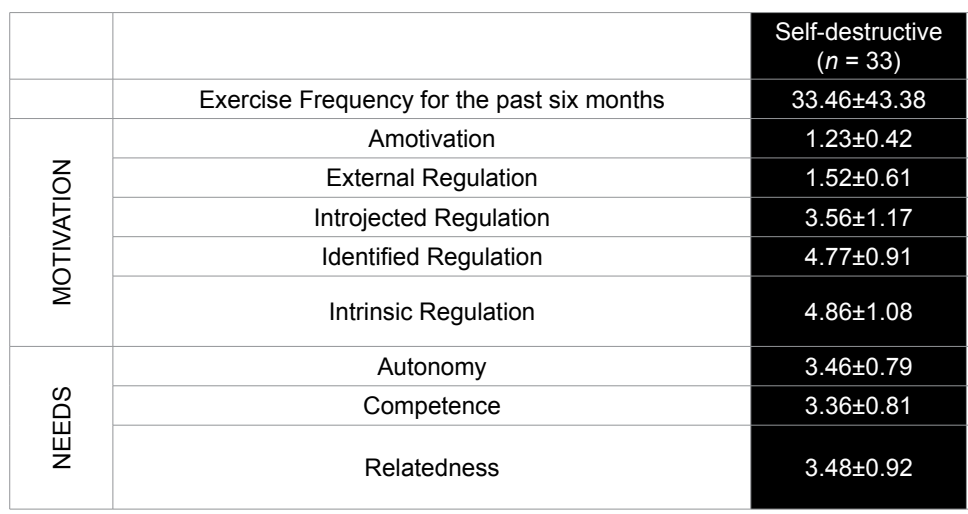

\begin{tabular}{|c|c|c|c|}
$\begin{array}{c}\text { Low Affective } \\
(n=41)\end{array}$ & $\begin{array}{c}\text { High Affective } \\
(n=40)\end{array}$ & $\begin{array}{c}\text { Self-fulfilling } \\
(n=29)\end{array}$ & $\begin{array}{c}\text { Total } \\
(N=143)\end{array}$ \\
\hline $27.33 \pm 22.58$ & $37.33 \pm 28.04$ & $29.24 \pm 22.37$ & $31.98 \pm 30.31$ \\
\hline $1.12 \pm 0.35$ & $1.15 \pm 0.33$ & $1.22 \pm 0.52$ & $1.18 \pm 0.40$ \\
\hline $1.24 \pm 0.54$ & $1.17 \pm 0.33$ & $1.15 \pm 0.31$ & $1.26 \pm 0.48$ \\
\hline $2.92 \pm 1.16$ & $3.45 \pm 1.23$ & $3.07 \pm 1.36$ & $3.24 \pm 1.24$ \\
\hline $4.58 \pm 1.00$ & $5.07 \pm 0.77$ & $5.06 \pm 0.70$ & $4.86 \pm 0.88$ \\
\hline $4.90 \pm 1.06$ & $5.31 \pm 0.63$ & $5.41 \pm 0.56$ & $5.11 \pm 0.90$ \\
\hline $3.71 \pm 0.74$ & $3.93 \pm 0.77$ & $4.10 \pm 0.69$ & $3.80 \pm 0.77$ \\
\hline $3.42 \pm 0.75$ & $3.93 \pm 0.66$ & $3.96 \pm 0.72$ & $3.66 \pm 0.78$ \\
\hline $3.59 \pm 0.84$ & $3.87 \pm 0.74$ & $4.08 \pm 0.78$ & $3.75 \pm 0.84$ \\
\hline
\end{tabular}

Table 1: Means and standard deviations $( \pm)$ in all variables for individuals with each distinctive profiles and the whole sample.

\section{Results and Discussion}

\section{Differences between individuals in exercise frequency during the past six months}

No differences were found between individuals at the extreme of the model (i.e., self-fulfilling vs. self-destructive, high affective vs. low affective). In addition, neither positive affect nor negative affect had a significant effect on participants exercise frequency during the past six months. Specifically, high positive affect was not associated with exercise frequency during the past six months when negative affect was low (self-fulfilling vs. low affective: $\mathrm{t}=-0.47, \mathrm{df}=62, \mathrm{p}=0.638$ ) or high (high affective vs. self-destructive: $\mathrm{t}=0.46, \mathrm{df}=72, \mathrm{p}=0.646$ ). Also in this line, high negative affect was not associated with exercise frequency during the past six months when positive affect was low (self-destructive vs. low affective: $\mathrm{t}=-0.77, \mathrm{df}=72, \mathrm{p}=0.442$ ) or high (high affective vs. self-fulfilling: $\mathrm{t}=1.28, \mathrm{df}=66, \mathrm{p}=.205)$. Nevertheless, one important observation was that both the individuals with a self-destructive (mean $=33.46)$ and those with a high affective profile $($ mean $=37.33)$ were the ones visiting the training facility at higher rate compared to individuals with a low affective (mean $=27.33$ ) or those with a self-fulfilling profile $($ mean $=29.24)$. Indeed, earlier research shows that individuals with low levels of negative affect (i.e., low affective and self-fulfilling) live a more balanced and harmonious life. Interestingly, individuals with a high affective or a self-destructive profile have a Type-A personality [17], which is characterized by aggressiveness, hostility, competitive spirit, fast pace, impatience and a tendency to engage in two or several activities concurrently, to interrupt when other people are speaking, and suffer from being a workaholic are postulated to present a Type A-personality [28]. Obviously, explaining why individuals with a selfdestructive or a high affective profile are more active visitors of the gym. Nevertheless, these differences were here not significant. See Table 1 for the details.

\section{Differences between individuals in motivation to exercise}

Individuals with a self-fulfilling profile scored lower in external regulation $(\mathrm{t}=2.93, \mathrm{df}=60, \mathrm{p}<0.05)$ and higher in intrinsic regulation $(\mathrm{t}$ $=2.48, \mathrm{df}=60, \mathrm{p}<0.05)$ compared to individuals with a self-destructive profile. Individuals with a high affective profile scored also higher than to those with a low affective profile in introjected regulation $(t=2.00$, $\mathrm{df}=79, \mathrm{p}<0.05)$, identified regulation $(\mathrm{t}=2.46, \mathrm{df}=79, \mathrm{p}<0.05)$ and intrinsic regulation $(t=2.08, d f=79, \mathrm{p}<0.05)$. In addition, positive affect was negatively associated to external regulation per se; both when negative affect was low (self-fulfilling vs. low affective) or high (high affective vs. self-destructive). Negative affect was positively associated to external regulation when positive affect was low (self-destructive vs. low affective), but not when positive affect was high (high affective vs. self-fulfilling). Introjected regulation was positively associated to negative affect, but only when positive affect was low (self-destructive vs. low affective). Positive affect was positively related to intrinsic regulation per se; both when negative affect was low (self-fulfilling vs. low affective) or high (high affective vs. self-destructive) (Table 2).

\section{Differences between individuals in basic psychological needs fulfillment by exercise habits}

Individuals with a self-fulfilling profile scored higher in autonomy $(\mathrm{t}=3.40, \mathrm{df}=61, \mathrm{p}<0.001)$, competence $(\mathrm{t}=3.11, \mathrm{df}=61, \mathrm{p}<0.01)$, and relatedness $(\mathrm{t}=2.77, \mathrm{df}=61, \mathrm{p}<0.01)$ compared to individuals with a self-destructive profile. Individuals with a high affective profile scored higher in competence $(\mathrm{t}=3.26, \mathrm{df}=79, \mathrm{p}<0.01)$ compared to individuals with a low affective profile. In short, the comparisons of profiles at the extreme of the model suggests that individuals with a selffulfilling profile experienced that their exercise program was of their own choice (i.e., autonomy), they were able to manage their training program (i.e., competence), and they felt comfortable with other people training at the same training facility (i.e., relatedness). In addition, positive affect was positively associated to autonomy, competence, and relatedness per se; both when negative affect was low (self-fulfilling vs. low affective) or high (high affective vs. self-destructive). Negative affect, on the other hand, was not related to any of the psychological needs (Table 3 ).

The relationship between exercise frequency, motivation, and basic psychological needs depending on individuals' type of affective profile

Correlation analyses showed that exercise frequency for the past six months was positively related to introjected regulation and identified regulation among individuals with a self-destructive profile and those with a high affective profile. These two motivation dimensions along intrinsic motivation were also positively related to exercise frequency for the past six months across the whole sample. In addition, external motivation was negatively related to exercise frequency in the whole sample. Nevertheless, no motivation dimension was associated to exercise frequency during the past six months for individuals with a low affective profile or for those with a self-fulfilling profile (Table 4).

With respect to basic psychological needs, correlation analyses showed that exercise frequency for the past six months was positively related to competence among individuals with a self-destructive profile. For individuals with a low affective profile, their training frequency was positively associated to both autonomy and competence. The 


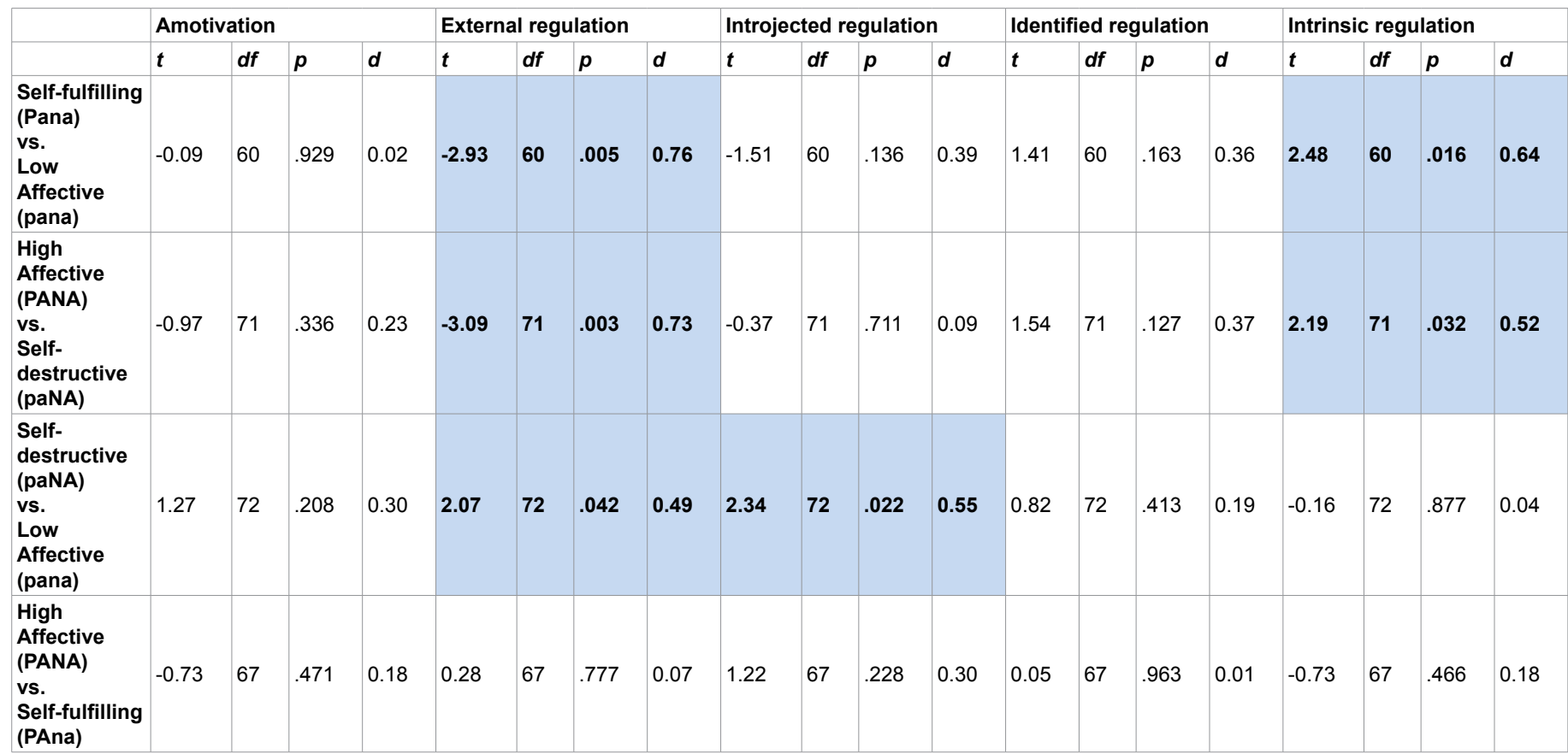

Table 2: Results of the matched t-test and the motivation variables. Note: PA = high positive affect; pa = low negative affect; NA = high negative affect; na low negative affect; $d=$ Cohen's $d$.

\begin{tabular}{|c|c|c|c|c|c|c|c|c|c|c|c|c|}
\hline & \multicolumn{4}{|c|}{ Autonomy } & \multicolumn{4}{|c|}{ Competence } & \multicolumn{4}{|c|}{ Relatedness } \\
\hline & $t$ & $d f$ & $p$ & $d$ & $t$ & $d f$ & $p$ & $d$ & $t$ & $d f$ & $p$ & $d$ \\
\hline $\begin{array}{l}\text { Self-fulfilling (Pana) } \\
\text { vs. } \\
\text { Low Affective (pana) }\end{array}$ & 3.40 & 61 & .001 & 0.87 & 3.11 & 61 & .003 & 0.80 & 2.77 & 61 & .008 & 0.71 \\
\hline $\begin{array}{l}\text { High Affective (PANA) } \\
\text { vs. } \\
\text { Self-destructive (paNA) }\end{array}$ & 2.54 & 71 & .013 & 0.60 & 3.36 & 71 & .001 & 0.80 & 1.98 & 71 & .052 & 0.47 \\
\hline $\begin{array}{c}\text { Self-destructive (paNA) } \\
\text { vs. } \\
\text { Low Affective (pana) }\end{array}$ & -1.42 & 72 & .161 & 0.33 & -0.36 & 72 & .722 & 0.08 & -0.52 & 72 & .604 & 0.12 \\
\hline $\begin{array}{l}\text { High Affective (PANA) } \\
\text { vs. } \\
\text { Self-fulfilling (PAna) }\end{array}$ & -0.98 & 68 & .328 & 0.24 & -0.16 & 68 & .870 & 0.04 & -1.17 & 68 & .244 & 0.28 \\
\hline
\end{tabular}

Table 3: Results of the matched t-test and the psychological needs variables. Note: PA = high positive affect; pa = low negative affect; NA = high negative affect; na low negative affect; $d=$ Cohen's $d$. Note: bold type indicates significant differences

same basic needs were positively associated to individuals with a high affective profile and to the whole sample. However, training frequency for the past six months was not associated to any of the psychological needs among individuals with a self-fulfilling profile (Table 4).

This study revealed differences in motivation and psychological needs depending on an individual's affective profile (Figure 1). By looking at the differences between individuals at the diametrical ends of the model, we first found that individuals with a self-fulfilling profile (i.e., high positive and low negative affect), compared to individuals with a self-destructive profile (i.e., low positive and high negative affect), scored low in external regulation and high in intrinsic regulation, autonomy, competence, and relatedness (see Figure 1, horizontal black arrows). This fits the description of a self-fulfilling profile as persistent, goal-directed, with high self-control and self-acceptance, resourceful, tolerant towards others, empathic, and helpful. In this line, at the other end of the diametrical comparisons, individuals with a high affective profile (high positive and high negative affect) scored higher in introjected regulation, identified regulation, intrinsic regulation, and competence than individuals with a low affective profile (low positive and low negative affect). See Figure 1, vertical black arrows. At first sight, suggesting that profiles characterized by high levels of positive affect are "better off" than those profiles characterized by low levels of positive affect.

One of the strengths of the affective profiles model, however, is that it allows the comparison of people who differ in one of the two affectivity dimensions while keeping the other constant. In this way we get to observe associations within this complex dynamic adaptive system [29]. For example, it is true that decreases in feeling motivated to exercise through cohesions from the environment (e.g., external regulation: "I train because other people say I should") seem to always lead to high positive affect independently of negative affect being high (see grey arrows in Figure 1: self-destructive vs. high affective) or low in (Figure 1: low affective vs. self-fulfilling). In contrast, decreases in this very same motivational dimension (i.e., external regulation) lead to low negative affect only when positive affect is low (see grey arrows in Figure 1: self-destructive vs. low affective) not when positive affect is high (see grey arrows in Figure 1: high affective vs. self-fulfilling). 
Citation: Garcia D, Archer T (2016) Affectivity Profiling in Relation to Exercise:Six-months Exercise Frequency, Motivation, and Basic Psychological Needs Fulfillment. Clin Exp Psychol 2: 128. doi:10.4172/2471-2701.1000128

Page 5 of 6

\begin{tabular}{|c|c|c|c|c|c|c|}
\hline & & Self-destructive & Low Affective & High Affective & Self-fulfilling & Total \\
\hline \multirow{5}{*}{ 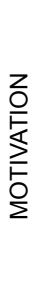 } & Amotivation & -0.18 & -0.22 & 0.04 & -0.30 & -0.16 \\
\hline & External Regulation & -0.30 & -0.24 & 0.11 & -0.03 & $-0.19^{*}$ \\
\hline & Introjected Regulation & $0.38^{*}$ & -0.09 & $0.42^{* *}$ & -0.16 & $0.19^{*}$ \\
\hline & Identified Regulation & $0.45^{\star}$ & 0.22 & $0.47^{* *}$ & -0.10 & $0.34^{* *}$ \\
\hline & Intrinsic Regulation & 0.22 & 0.25 & 0.25 & 0.13 & $0.24^{* *}$ \\
\hline \multirow{3}{*}{$\begin{array}{l}\mathscr{0} \\
\text { 岂 } \\
\text { س }\end{array}$} & Autonomy & 0.34 & $0.34^{*}$ & $0.41^{*}$ & 0.04 & $0.31^{* \star *}$ \\
\hline & Competence & $0.38^{*}$ & $0.35^{*}$ & $0.40^{*}$ & 0.04 & $0.33^{* * *}$ \\
\hline & Relatedness & 0.04 & 0.20 & 0.14 & 0.14 & 0.12 \\
\hline
\end{tabular}

Table 4: Pearson's correlation coefficients $(r)$ between exercise frequency during the past six months and both motivation to exercise and psychological needs fulfillment for individuals with distinct profiles and the whole sample. Controlled by gender. Note: ${ }^{*} p<0.05,{ }^{* *} p<0.01,{ }^{* *} p<0.001$.

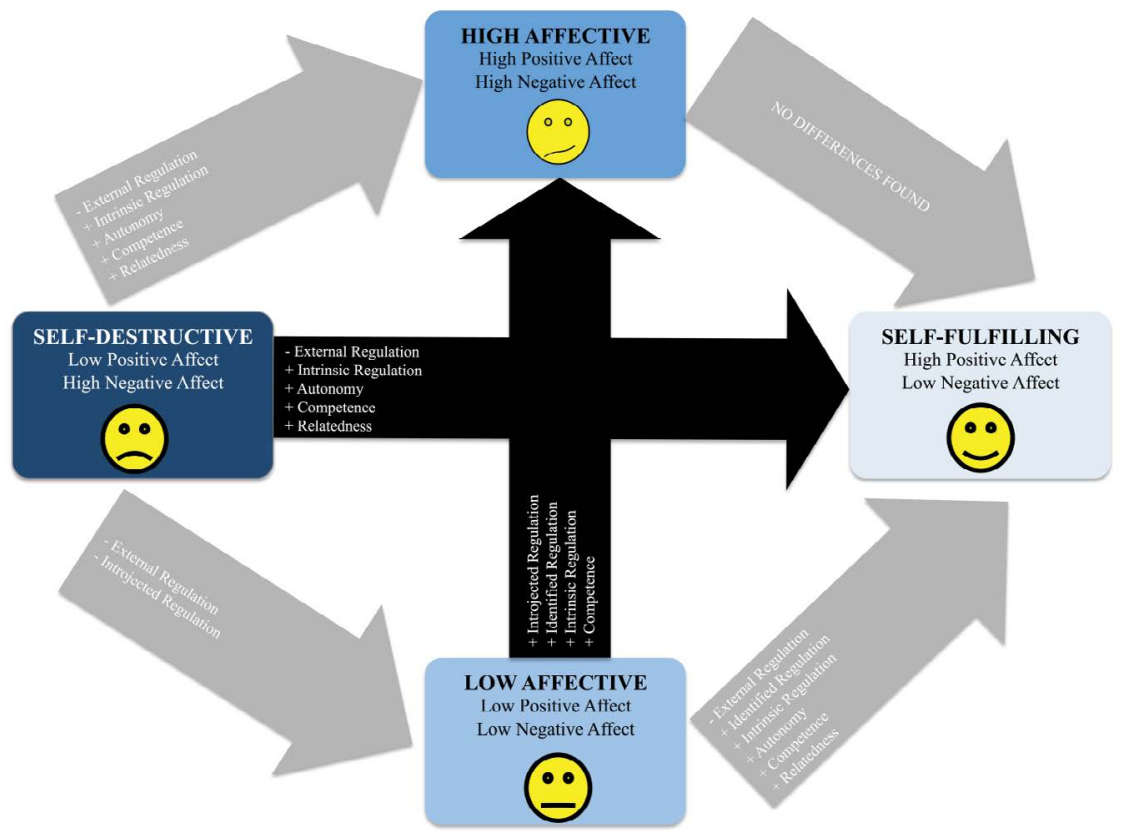

Figure 1: The black arrows show the differences found between individuals with affective profiles that are at the extremes of the model: self-destructive versus self-fulfilling (low-high positive affect, high-low negative affect) and low affective versus high affective (low-high positive affect, low-high negative affect). The grey arrows show the differences found when individuals were matched in one affective dimension, and differed in the other (i.e., within differences): self-destructive versus high affective (matching: high-high negative affect, differing: low-high positive affect), self-destructive versus low affective (matching: low-low positive affect, differing: high-low negative affect), high affective versus self-fulfilling (matching: high-high positive affect, differing: high-low negative affect), and low affective versus self-fulfilling (matching: low-low negative affect, differing: low- high positive affect).

Note. Reprinted with permission from Well-Being and Human Performance Sweden AB.

\section{Conclusion and Final Remarks}

Future studies are needed in order to further investigate objective measures of exercise frequency in relation to a person's affective profile. All the interactions detailed in Figure 1, give a picture of the complexity of the association of both exercise motivation dimensions and psychological needs fulfillment by exercise to a person's affectivity system - an adaptive complex dynamic system.

"General Systems Theory, a related modern concept [to holism], says that each variable in any system interacts with the other variables so thoroughly that cause and effect cannot be separated. A simple variable can be both cause and effect. Reality will not be still. And it cannot be taken apart! You cannot understand a cell, a rat, a brain structure, a family, a culture if you isolate it from its context. Relationship is everything." Marilyn Ferguson

\section{Acknowledgements}

We would like to thank Björn Mikmar and his most helpful staff at Friskis\&Svettis Karlskrona/Ronneby for their collaboration in the collection of the data. We would also like to convey our gratitude to the participants for spending their valuable time answering the questionnaires and to both Patricia Rosenberg and Erik Lindskär for his help with the data collection. Last but not the least we want to thank Sophia Isabella Garcia Rosenberg and Linnéa Mercedes Garcia Rosenberg for their help with the creation of Figure 1.

\section{Funding}

The Swedish National Centre for Research in Sports (Grant nr. P2012-0097) and the Bliwa Stiftelsen supported the development of this article. The funders 
Citation: Garcia D, Archer T (2016) Affectivity Profiling in Relation to Exercise:Six-months Exercise Frequency, Motivation, and Basic Psychological Needs Fulfillment. Clin Exp Psychol 2: 128. doi:10.4172/2471-2701.1000128

Page 6 of 6

had no role in study design, data collection and analysis, decision to publish, or preparation of the manuscript.

\section{Conflict of Interest}

Dr. Danilo Garcia is the Director of the Blekinge Center of Competence, which is the Blekinge County Council's research and development unit. The Center works on innovations in public health and practice through interdisciplinary scientific research, person-centered methods, community projects, and the dissemination of knowledge in order to increase the quality of life of the habitants of the county of Blekinge, Sweden.

\section{References}

1. Archer T, Adrianson L, Plancak A, Karlsson E (2007) Influence of affective personality on cognitive-mediated emotional processing: need for empowerment. European Journal of Psychiatry 21: 21-44.

2. Garcia D (2011) Adolescents' happiness: the role of the affective temperament model on memory and apprehension of events, subjective well-being and psychological well-being. PhD thesis, University of Gothenburg, Gothenburg, Sweden.

3. Norlander T, Bood SÅ, Archer T (2002) Performance during stress: affective personality, age and regularity of physical exercise. Social Behavior and Personality 30: 495-508.

4. Norlander T, von Schedvin $\mathrm{H}$, Archer $\mathrm{T}(2005)$ Thriving as a function of affective personality: relation to personality factors, coping strategies and stress. Anxiety Stress Coping 18: 105-116.

5. Garcia D, Rosenberg P, Erlandsson A, Siddiqui A (2010) On Lions and Adolescents: Affective Temperaments and the Influence of Negative Stimuli on Memory. Journal of Happiness Studies 11: 477-495.

6. Garcia D, Kerekes N, Andersson-Arntén AC, Archer T (2012) Temperament Character, and Adolescents' Depressive Symptoms: Focusing on Affect. Depression Research and Treatment.

7. Garcia D, Siddiqui A (2009a) Adolecents' affective temperaments: life satisfaction, interpretation and memory of events. The Journal of Positive Psychology 4: 155-167.

8. Garcia D, Siddiqui A (2009b) Adolecents' psychological well-being and memory life events influences on life satisfaction with respect to temperamental dispositions. Journal of Happiness Studies 10: 407-419.

9. Garcia D, Moradi S (2013) The affective temperaments and well-being: Swedish and Iranian adolescents' life satisfaction and psychological well-being. Journal of Happiness Studies 14: 689-707.

10. Garcia D (2012) The affective temperaments: differences between adolescents in the big five model and Cloninger's psychobiological model of personality. Journal of Happiness Studies 13: 999-1017.

11. Nima AA, Rosenberg P, Archer T, Garcia D (2013) Anxiety, Affect, Self-esteem, and Stress: Mediation and Moderation Effects on Depression. PLOS ONE.

12. Bood SÅ, Archer T, Norlander T (2004) Affective personality in relation to general personality, self-reported stress, coping and optimism. Individual Differences Research 2: 26-37.
13. Garcia D, Nima AA, Kjell ONE (2014) The affective profiles, psychological wellbeing, and harmony: environmental mastery and self-acceptance predict the sense of a harmonious life. PeerJ 2: e259.

14. Palomo T, Kostrzewa RM, Beninger RJ, Archer $\mathrm{T}$ (2007) Treatment consideration and manifest complexity in comorbid neuropsychiatric disorders. Neurotoxicity Research 12: 43-60.

15. Palomo T, Beninger RJ, Kostrzewa RM, Archer T (2008) Focusing on symptoms rather than diagnoses in brain functions: conscious and nonconscious expression in impulsiveness and decision making. Neurotoxicity Research 14: 1-20.

16. Schütz E, Archer T, Garcia D (2013) Character profiles and adolescents' selfreported affect. Personality and Individual differences 54: 841-844.

17. Schütz E, Garcia D, Archer T (2014) Affective state, stress, and type a-personality as a function of gender and affective profiles. International Journal of Research Studies in Psychology 3: 51-64.

18. Schütz E, Sailer U, Nima A, Rosenberg P, Andersson-Arntén AC, et al. (2013) The affective profiles in the USA: happiness, depression, life satisfaction, and happiness-increasing strategies. PeerJ 1: e156.

19. Di Fabio A, Bucci O (2015) Affective profiles in Italian high school students: life satisfaction, psychological well-being, self-esteem, and optimism. Frontiers in Psychology 6: 1310.

20. De Caroli ME, Sagone E (2006) Resilience and psychological well-being differences for affective profiles in Italian middle and late adolescents.

21. Garcia D, Sailer U, Nima AA, Archer T (2016) Questions of Time and Affect: A Person's Affectivity Profile, Time Perspective, and Well-Being. PeerJ 4: e1826.

22. Watson D, Clark LA, Tellegen A (1988) Development and validation of brief measures of positive and negative affect: The PANAS scale. Journal of Personality and Social Psychology 54: 1063-1070.

23. Garcia D, MacDonald S, Archer T (2015) Two different approaches to the affective profiles model: median splits (variable-oriented) and cluster analysis (person-oriented). PeerJ 3: e1380.

24. Deci EL, Ryan RM (1985) Intrinsic motivation and self-determination in human behavior. New York.

25. Markland D, Tobin V (2004) A modification to Behavioural Regulation in Exercise Questionnaire to include an assessment of amotivation. Journal of Sport and Exercise Psychology 26: 191-196.

26. Deci EL, Ryan RM (2000) The "what" and "why" of goal pursuits: Human needs and the self-determination of behavior. Psychological Inquiry 11: 227-268.

27. Vlachopoulos SP, Michailidou S (2006) Development and Initial Validation of a Measure of Autonomy, Competence, and Relatedness in Exercise: The Basic Psychological Needs in Exercise Scale. Measurement in Physical Education and Exercise Science 10: 179-201.

28. Friedman HS, Booth-Kewley S (1988) Validity of the Type-A construct: reprise. Psychol Bull 104: 381-384.

29. Sailer U, Rosenberg P, Nima AA, Gamble A, Gärling T, et al. (2014) A Happie and Less Sinister Past, a More Hedonistic and Less Fatalistic Present and a more Structured Future: Time Perspective and Well-Being. Peer J 2: e303. 